\title{
Atrial septal aneurysm in adult patients: spectrum of clinical, echocardiographic presentation and to propose a new classification on the basis of trans-thoracic-two-dimensional echocardiography
}

\author{
Rajendra Kumar Jatav ${ }^{1}$, Mamta B. Kumbhare ${ }^{2}$, T. Surender ${ }^{3}$, \\ Ch. Rachan ${ }^{4}$, T. V. Vamshi Krishna ${ }^{4}$
}

\begin{abstract}
${ }^{1}$ Associate Professor, ${ }^{3}$ Professor, ${ }^{4}$ P.G. Student, Department of Medicine, CAIMS, Bommakal, Karimnagar - 505001, A. P., India, ${ }^{2}$ Senior Specialist, Department of Anesthesia, Dhanvanthari Hospital, NTPC, RSTPS, Karimnagar 505215 A.P., India

Received: 23 March 2014

Revised: 4 April 2014

Accepted: 6 April 2014

*Correspondence:

Dr. Rajendra Kumar Jatav,

E-mail: krajendramamta@gmail.com

(C) 2014 Jatav RK et al. This is an open-access article distributed under the terms of the Creative Commons Attribution Non-Commercial License, which permits unrestricted non-commercial use, distribution, and reproduction in any medium, provided the original work is properly cited.
\end{abstract}

\begin{abstract}
An atrial septal aneurysm is a rare but well recognized cardiac abnormality of uncertain clinical relevance. ASA is definitively associated with congenital and acquired heart diseases but also can be presented as an isolated and totally asymptomatic entity. On the basis of our TTE finding we are proposing a new classification of ASA. We have classified ASA in to two major types: (A) Localized, and (B) Generalized. Both major types are further Sub-classified into 5 possible types on the basis of movements of ASA. New classification of ASA is as follows (1) A/B Type 1R: if the bulging is in the RA only (2) A/B Type 2L: if the bulging is in the LA only (3) A / B Type 3RL : if the major excursion bulges to the RA and lesser excursion bulges toward LA (4) A/B Type 4LR: if the maximal excursion of the atrial septal aneurysm is toward the LA with a lesser excursion toward the RA (5) A / B Type 5: if the atrial septal aneurysm movement is bidirectional and equidistant to both atria during the cardiorespiratory cycle. We found higher prevalence $(2.24 \%)$ of ASA. A/B Type 2L and A/B Type 4LR were most common types. All type of ASA had particular clinical and echocardiographic characteristics. Mobile ASA and ASA with $>10$ mm excursion are associated with a higher risk of stroke.
\end{abstract}

Keywords: Atrial septal aneurysm, Embolism, Echocardiography

\section{INTRODUCTION}

An atrial septal aneurysm is a localized (saccular shape) or generalized deformity of the interatrial septum (IAS). Generally ASA is a localized deformity of the interatrial septum and occurs at the level of fossa ovalis ${ }^{1}$ but rarely it may involve entire atrial septum ${ }^{2}$ which bulges into the right or left atrium or both. However, this definition of ASA is arbitrary. ASA was initially thought to be a rare congenital abnormality but with the advent of twodimensional echocardiography and more recently the widespread use of echocardiography it has been more easily and more frequently identified in patients. ${ }^{3,4}$ Prevalence of ASA varies but TTE studies estimate the rate to between $0.08 \%$ and $1.2 \% .^{5-14}$ In a large autopsy series the prevalence reported was $1 \% .^{1}$ More recent studies with TEE have shown prevalence between $2 \%$ and $10 \% .^{16,18}$ ASA has been associated with congenital heart diseases such as PFO, ASD, VSD, etc. It is also associated with acquired heart diseases including valvular diseases, CMP, HTN, PHTN etc. More recently a number of studies found an association between ASA and CVE of embolic origin. 


\section{Objectives}

The aim of the study is to find the prevalence, morphological type of atrial septal aneurysm, ASA associated abnormalities and to propose a new classification of ASA on the basis of trans-thoracic two dimensional echocardiography findings.

\section{METHODS}

This was a prospective, longitudinal, single center study conducted by the department of medicine at Chalmeda Anand Rao institute of medical sciences, a semi-urban tertiary care teaching hospital - Bommakal - KarimnagarAndhra Pradesh - India, over a period of five years from January 2009 to January 2014. All adult patients between 18 to 93 year of age, who referred or presented to our department were included in the present study. Those suspected of having an ASA were further evaluated: clinically, with twelve-lead-surface electrocardiography, chest radiography and Holter monitoring and the diagnosis were confirmed by TTE. All patients underwent trans-thoracic-two-dimensional echocardiography, M-mode, color flow Doppler and spectral Doppler echocardiography. During the study period, we studied 15234 patients which were referred for TTE. Of these, 370 patients fulfilled the echocardiographic criteria for ASA. The Echocardiographic studies were performed using two commercially available cardiac ultrasound systems (ESAOTE - Megas-GPX and Phillips Clear View 550) with 2.5 to $4 \mathrm{MHz}$ phased array imaging transducers. Both systems were capable of M-mode, color flow Doppler and spectral Doppler echocardiography. All patients underwent standard TTE views including Parasternal Long Axis (PLAX), Parasternal Short Axis (PSAX), Parasternal High Short Axis View (PHSX), supra sternal view, apical 2, 3, 4 and 5 chamber views as well as subcostal four chamber and short axis views. The studies were performed with the patient in supine and left lateral decubitus positions during quiet respiration. Particular attention was given to subcostal views with appropriate transducer angulations to visualize the heart completely in 4 chamber view and the IAS with its foramen ovale segment was visualized in particular The atria, including the atrioventricular valves was magnified to ease the visualization of movements and measurement of ASA. Patients were placed in supine position with legs and knees flexed. They were in quiet respiration and sustained inspiration. Contrast echocardiography studies were performed with the use of agitated saline solution in whom intracavitary shunt was suspected. Ten milliliters of vigorously agitated saline solution was injected in an antecubital vein during normal respiration and during a series of coughs or Valsalva maneuver. Diagnosis of PFO was made if micro bubbles were observed in the left atrium during the first three or four heart beats of opacification of the right atrium. ASD was diagnosed if a clean area (negative effect) was produced near the IAS when the right atrium (RA) was opacificated by the micro bubbles.

Criteria for ASA: The diagnostic criteria for ASA were made if a sacculation type of deformity in the interatrial septum or the foramen ovale region was seen. An excursion of $>10 \mathrm{~mm}$ beyond the plain of the atrial septum into the right or left atrium or if the sum of bilateral excursions of $>10 \mathrm{~mm}$ was required. The minimal aneurysmal base amplitude (width) accepted in this study was $15 \mathrm{~mm}$ in diameter. The aneurysm was observed in subcostal, AP4C and PSAX views at the level of the great vessels. Sometimes the bulging was also seen in apical 2 and 3 chamber views. Patients with mitral prosthesis or who had any cardiothoracic surgery involving the atrial septum were excluded from the study. MVP and TVP were diagnosed in the PLAX view, Mmode, and apical 2 and 4 chamber views using as diagnostic criteria of any leaflets prolapsing behind the plane of the valve annulus in at least two different views and the presence of any degree of valvular regurgitation. All the studies were taped, and hard copies were taken for further analysis, measurements \& reviewed by all authors.

\section{RESULTS}

A total 15234 patients had complete TTE in our institution during the study period. Three hundred seventy patients $(2.42 \%)$ fulfilled the echocardiographic criteria for ASA. Of these 370 patients, 236 were women $(63.78 \%)$ and 134 were men $(36.21 \%)$ and a female/male ratio $1.7: 1$. The age range was 18 to 93 years, with a mean of 56 years at the time of study (Table 7). The ASA excursion was measured until the maximal dimension and the width of fossa ovalis were obtained. The minimal ASA excursion and the aneurysmal base diameter used for inclusion were $10 \mathrm{~mm}$ and $15 \mathrm{~mm}$, respectively. Using this criteria we found that the atrial septal excursion in our 370 patients ranged from $10 \mathrm{~mm}$ to 40 $\mathrm{mm}$ (mean $14 \mathrm{~mm}$ ) and the aneurysmal base diameter (width) ranged from $15 \mathrm{~mm}$ to $30 \mathrm{~mm}$ (mean $20 \mathrm{~mm}$ ). Table 1 summarizes the morphological characteristics of the ASA as determined by TTE. Overall of the whole group $82.70 \%$ had localized and $17.19 \%$ had generalized ASA. Predominant bulging was towards the LA as compare to bulging towards RA (Table 5). 51\% the ASA showed spontaneous oscillations between the two atria during a normal cardiorespiratory cycle (Table 6). Echocardiographic characteristics of ASA (Table 7) by its type are as follows: (1) A/B, Type 1R (11.35\%): 42 patients diagnosed with this type. Of these, $76.19 \%$ were women. CAD was documented in $16.66 \%$ and LAE was found in $21.42 \%$. ASD in three $(7.14 \%)$ and DCMP in two $(4.76 \%)$ patients were observed. In both DCMP patients EF was $<20 \%$. (2) A/B, Type 2L (38.37\%): This is the most common type of ASA. Generalized type is more common in this group. 45 patients had history of HTN, 44 had DM, and 8 had PHTN. Twenty two had $(15.49 \%)$ CAD. RAE found in 55 and RVE in 10 
patients. LVH diagnosed in 68 patients with this group. Ten patients diagnosed with DCMP and of this six had EF was $<30 \%$ and in remaining four it was $<40 \%$. In CRF patients this ASA type was commonest. (3) A/B, Type 3 RL (15.40\%): AR was seen in 18 (31.57\%) and MVP in $9(15.78 \%)$ patients. The DCMP was present in 4 patients and these entire patient had $E F<30 \%$. (4) $A / B$ Type 4LR (28.64\%): This is the second most common type of ASA. CVE was more frequently observed in this group.

Table 1: Proposed new classification of atrial septal aneurysm.

\begin{tabular}{|ll|}
\hline Class & $\begin{array}{l}\text { The ASA protrudes from midline of } \\
\text { the atrial septum to the right atrium } \\
\text { throughout the cardio respiratory } \\
\text { cycle. }\end{array}$ \\
\hline A/B, Type 2 L & $\begin{array}{l}\text { The ASA protrudes from midline of } \\
\text { the atrial to the left atrium } \\
\text { throughout the cardio respiratory } \\
\text { cycle. }\end{array}$ \\
\hline A/B, Type 3 RL & $\begin{array}{l}\text { The maximal excursion of the ASA } \\
\text { is toward the right atrium with a } \\
\text { lesser excursion toward the left } \\
\text { atrium. }\end{array}$ \\
\hline A/B, Type 4 LR & $\begin{array}{l}\text { The maximal excursion of the ASA } \\
\text { is toward the left atrium with a lesser } \\
\text { excursion toward the right atrium. }\end{array}$ \\
\hline A/B, Type 5 & $\begin{array}{l}\text { The ASA movements is bidirectional } \\
\text { and equidistant to the right as well as } \\
\text { to the left atrium during the cardio } \\
\text { respiratory cycle. }\end{array}$ \\
\hline
\end{tabular}

Table 2: Clinical variables in the present study.

\begin{tabular}{|lll|}
\hline Clinical variables & Number & $\%$ \\
\hline Systemic Hypertension (HTN) & 114 & $30.81 \%$ \\
\hline Diabetes Mellitus (DM) & 105 & $28.37 \%$ \\
\hline Coronary Artery Disease (CAD) & 52 & $14.05 \%$ \\
\hline Chronic Renal Failure (CRF) & 27 & $7.29 \%$ \\
\hline $\begin{array}{l}\text { Chronic Obstructive Pulmonary } \\
\text { Disease (COPD) }\end{array}$ & 23 & $6.21 \%$ \\
\hline Pulmonary Hypertension (PHTN) & 22 & $5.94 \%$ \\
\hline Heart Failure (HF) & 12 & $3.24 \%$ \\
\hline Cerebrovascular Events (CVE) & 09 & $2.43 \%$ \\
\hline $\begin{array}{l}\text { Supra-Ventricular Tachyarrhythmia } \\
\text { (SVTA) }\end{array}$ & 06 & $1.62 \%$ \\
\hline
\end{tabular}

Patients with TVP had highest percentage (47.05\%) in this group. PFO was diagnosed in 6 patients. SVTA was present in 2 patients, one had atrial fibrillation and other had atrial flutter. COPD was present in 5 patients and all these patients had RBBB. CAD was detected in 16 patients; of these 4 patients had LBBB. One patient diagnosed with VSD and (5) A/B, Type 5 (6.21\%): This type represents the smallest group. The most relevant finding here is mitral valve and aortic valve calcification with sclerosis. A.S. was present in 3 patients and 2 had history of syncopal attack. One patient diagnosed with M.S.

Table 3: Echocardiographic variables in the present study.

\begin{tabular}{|lll|}
\hline Echocardiographic variables & Number & $\%$ \\
\hline Total patients with valvulopathies & 297 & 80.27 \\
\hline Tricuspid valve Regurgitation (TR) & 221 & 59.72 \\
\hline Left Ventricular hypertrophy (LVH) & 160 & 43.24 \\
\hline Mitral valve Regurgitation (MR) & 150 & 40.54 \\
\hline Calcification Aortic Sclerosis (CAS) & 146 & 39.45 \\
\hline Patent Foramen Ovale (PFO) & 42 & 11.35 \\
\hline Left Atrial Enlargement (LAE) & 109 & 29.45 \\
\hline Mitral Annular Calcification (MAC) & 101 & 27.29 \\
\hline Aortic valve regurgitation (AR) & 88 & 23.78 \\
\hline $\begin{array}{l}\text { Mitral and Aortic Calcification } \\
\text { (MAC + CAS) }\end{array}$ & 86 & 23.24 \\
\hline Right Atrial Enlargement (RAE) & 60 & 16.21 \\
\hline $\begin{array}{l}\text { Ejection Fraction (EF), >50\% and } \\
\text { <50\% }\end{array}$ & $320 \&$ & 86.48 \\
\hline Total patients without valvulopathies & 58 & 13.51 \\
\hline $\begin{array}{l}\text { Valvular Prolapse (VP): (MVP,TVP } \\
\text { and MTVP) }\end{array}$ & 47 & 15.67 \\
\hline Left Ventricular Enlargement (LVE) & 40 & 12.70 \\
\hline Right Ventricular Enlargement (RVE) & 38 & 10.81 \\
\hline Atrial Septal Defect (ASD) & 29 & 7.83 \\
\hline Dilated Cardiomyopathy (DCMP) & 26 & 7.02 \\
\hline Aortic Valve Stenosis (AS) & 13 & 3.51 \\
\hline Valvular Vegetations (VEG) & 9 & 2.43 \\
\hline $\begin{array}{l}\text { Intra cardiac mass: thrombus (5) and } \\
\text { tumor (1) }\end{array}$ & 6 & 1.62 \\
\hline Ventricular Septal Defect (VSD) & 5 & 1.35 \\
\hline Eustachian Valve (EV), [Prominent] & 4 & 1.08 \\
\hline Mitral Valve Stenosis & 3 & 0.81 \\
\hline
\end{tabular}

Table 4: Major types and sub-types of ASA according to proposed new classification.

\begin{tabular}{|llll|}
\hline $\begin{array}{l}\text { Sub } \\
\text { type of } \\
\text { ASA }\end{array}$ & $\begin{array}{l}\text { Major type ASA } \\
\text { Localized (A) }\end{array}$ & Generalized $(\mathbf{B})$ & $(\mathbf{A}+\mathbf{B})$ \\
\hline $\begin{array}{l}\text { Type } \\
1 \mathrm{R}\end{array}$ & $35(11.43 \%)$ & $07(10.93 \%)$ & $42(11.35 \%)$ \\
\hline $\begin{array}{l}\text { Type } \\
\text { 2L }\end{array}$ & $112(36.60 \%)$ & $30(46.87 \%)$ & $142(38.37 \%)$ \\
\hline $\begin{array}{l}\text { Type } \\
\text { 3RL }\end{array}$ & $51(16.66 \%)$ & $06(9.37 \%)$ & $57(15.40 \%)$ \\
\hline $\begin{array}{l}\text { Type } \\
\text { 4LR }\end{array}$ & $86(28.10 \%)$ & $20(31.25 \%)$ & $106(28.64 \%)$ \\
\hline Type 5 & $22(7.18 \%)$ & $01(1.56 \%)$ & $23(6.21 \%)$ \\
\hline $\begin{array}{l}\text { Total } \\
\text { number }\end{array}$ & $306(82.70 \%)$ & $64(17.29 \%)$ & 370 \\
\hline
\end{tabular}


Table 5: Predominant excursion (Bulging) of ASA.

\begin{tabular}{|c|c|c|c|}
\hline \multicolumn{2}{|c|}{$\begin{array}{l}\text { Toward left atrium } \\
{[248(71.46 \%)]}\end{array}$} & \multicolumn{2}{|c|}{$\begin{array}{l}\text { Toward right atrium } \\
{[99(28.53 \%)]}\end{array}$} \\
\hline $\begin{array}{l}\text { A/B } \\
\text { Type 2L }\end{array}$ & $142(57.25 \%)$ & $\begin{array}{l}\text { A/B } \\
\text { Type 1R }\end{array}$ & $42(42.42 \%)$ \\
\hline $\begin{array}{l}\text { A/B } \\
\text { Type 4LR }\end{array}$ & $106(42.74 \%)$ & $\begin{array}{l}\text { A/B } \\
\text { Type 3RL }\end{array}$ & $57(57.57 \%)$ \\
\hline
\end{tabular}

[A/B Type 5 ASA $(n=23)$ was excluded because this type do not have atrial predominance]

Table 6: Mobile and fixed types ASA.

\begin{tabular}{|c|c|c|c|}
\hline \multicolumn{2}{|c|}{$\begin{array}{l}\text { Mobile ASA } \\
{[186(51 \%)]}\end{array}$} & \multicolumn{2}{|c|}{$\begin{array}{l}\text { Fixed ASA } \\
{[184(49 \%)]}\end{array}$} \\
\hline $\begin{array}{l}\text { A/B } \\
\text { Type 3RL }\end{array}$ & $57(30.64 \%)$ & $\begin{array}{l}\text { A/B } \\
\text { Type 1R }\end{array}$ & $42(22.82 \%)$ \\
\hline $\begin{array}{l}\text { A/B } \\
\text { Type 4LR }\end{array}$ & $106(56.18 \%)$ & $\begin{array}{l}\text { A/B } \\
\text { Type 2L }\end{array}$ & $142(77.17 \%)$ \\
\hline $\begin{array}{l}\text { A/B } \\
\text { Type } 5\end{array}$ & $23(12.36 \%)$ & - & - \\
\hline
\end{tabular}

Intracardiac thrombi were found in 5 patients. Thrombi were located within the left atrial appendage and within the LV cavity. CVE were associated with ASA in 9 patients. A history of atrial arrhythmias was obtained in 6 patients, 4 had atrial fibrillation and 2 had atrial flutter. A history of syncope was found in 4 patients. Only two patients with syncope had evidence of arrhythmias. 43 patients showed echocardiographic evidence of intracavitary shunt. ASD was detected in 29 patients (16 women and 13 men). In ASD patients predominant bulging was towards LA [ $(n=17), 58.62 \%]$. One patient had severe PHTN, RVE and right to left shunt. PFO was diagnosed in 42 patients, out of these 14 patients $(33.33 \%)$ were diagnosed by contrast echocardiography. Predominant bulging in PFO was towards LA $[n=38$, $(90.47 \%)]$. Only one patient had a history of CVE and it was associated with PFO. Two had primary PHTN and 22 patients had secondary PHTN. In COPD patients the predominant bulging was towards LA \& where as in VSD it was towards RA. Other clinical variables associated with ASA like; HTN, DM, CAD, CVE, CRF, COPD, PHTN, HF and arrhythmias are identified in our study were described in Table $2 \& 7$. Echocardiographic variables diagnosed in present study were described in Table $3 \& 7$.

Table 7: Clinical and echocardiographic characteristics of ASA.

\begin{tabular}{|lllllllllll|}
\hline ASA type & $\begin{array}{l}\text { Age } \\
(\text { yr. })\end{array}$ & $\begin{array}{l}\text { HTN } \\
(\mathbf{1 1 4})\end{array}$ & $\begin{array}{l}\text { DM } \\
(\mathbf{1 0 5})\end{array}$ & $\begin{array}{l}\text { CAD } \\
(\mathbf{5 2})\end{array}$ & $\begin{array}{l}\text { CRF } \\
(\mathbf{2 7})\end{array}$ & $\begin{array}{l}\text { COPD } \\
(\mathbf{2 3})\end{array}$ & $\begin{array}{l}\text { PHTN } \\
(\mathbf{2 2})\end{array}$ & $\begin{array}{l}\text { HIF } \\
(\mathbf{1 2})\end{array}$ & $\begin{array}{l}\text { CVE } \\
(\mathbf{0 9})\end{array}$ & $\begin{array}{l}\text { SVTA } \\
(\mathbf{0 6})\end{array}$ \\
\hline $\begin{array}{l}\text { Type 1R } \\
\text { 42 }(11.35 \%)\end{array}$ & $\begin{array}{l}18-90 \\
(54)\end{array}$ & $11(26.19 \%)$ & $11(26.19)$ & $7(16.66)$ & $4(9.52)$ & $1(2.38)$ & $2(4.76)$ & $3(7.14)$ & $1(2.38)$ & $2(4.76)$ \\
\hline $\begin{array}{l}\text { Type } 2 \mathrm{~L} \\
142(38.37 \%)\end{array}$ & $\begin{array}{l}22-87 \\
(56)\end{array}$ & $45(31.69 \%)$ & $44(30.98)$ & $22(15.49)$ & $8(5.63)$ & $09(6.33)$ & $08(5.63)$ & $3(2.11)$ & $2(1.40)$ & $1(0.70)$ \\
\hline $\begin{array}{l}\text { Type 3RL } \\
57(15.40 \%)\end{array}$ & $\begin{array}{l}25-78 \\
(52)\end{array}$ & $18(31.57 \%)$ & $16(28.07)$ & $06(10.52)$ & $4(7.01)$ & $05(8.77)$ & $04(7.01)$ & $2(3.50)$ & $1(1.75)$ & $1(1.75)$ \\
\hline $\begin{array}{l}\text { Type 4LR } \\
106(28.64 \%)\end{array}$ & $\begin{array}{l}28-89 \\
(59)\end{array}$ & $33(31.13 \%)$ & $32(30.18)$ & $16(15.09)$ & $7(6.60)$ & $05(4.71)$ & $06(5.66)$ & $2(1.88)$ & $3(2.83)$ & $2(1.88)$ \\
\hline $\begin{array}{l}\text { Type 5 } \\
23(6.21 \%)\end{array}$ & $\begin{array}{l}38-93 \\
(66)\end{array}$ & $7(30.43 \%)$ & $2(8.69)$ & $1(4.34)$ & $4(17.39)$ & $3(13.04)$ & $02(8.69)$ & $2(8.69)$ & $2(8.69)$ & 00 \\
\hline
\end{tabular}

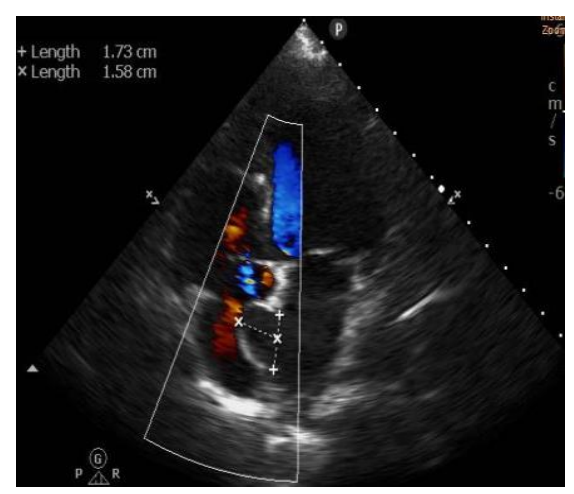

Figure 1: Inverted AP4C view shows localized Type 1R ASA.

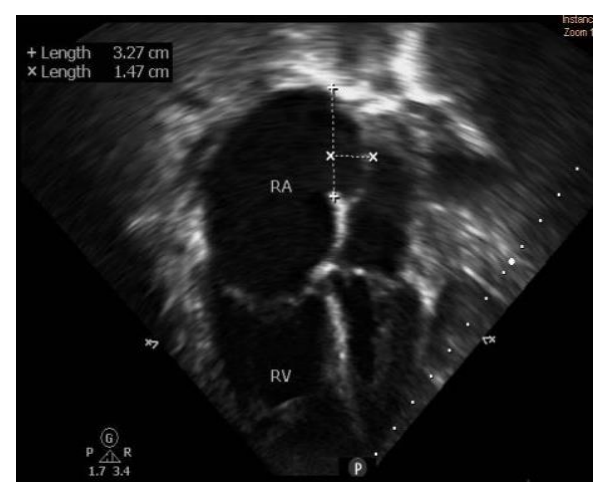

Figure 2: AP4C view shows localized Type 2L ASA. [RA: Right atrium, RV: Right ventricle]. 


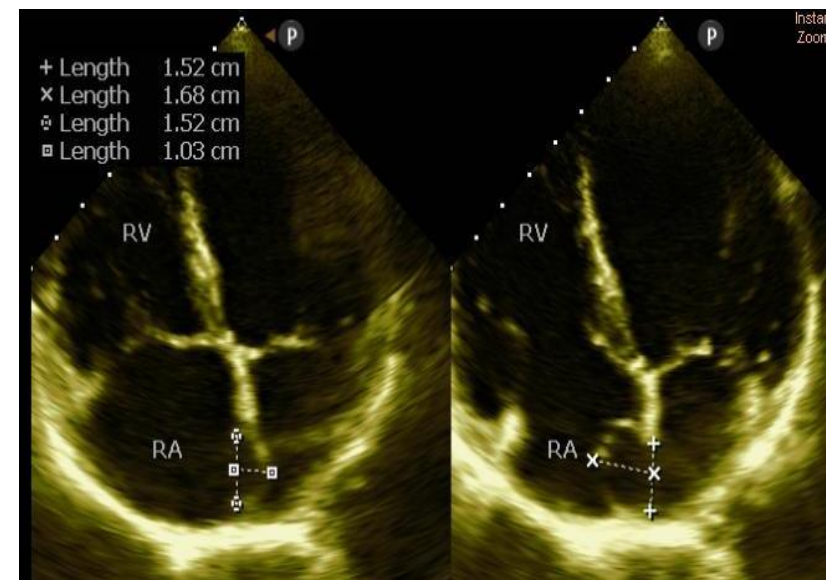

Figure 3: Localized Type 3RL ASA; inverted AP4C view shows, maximal excursion of aneurysm toward RA (left frame) and lesser excursion toward LA (Right frame).

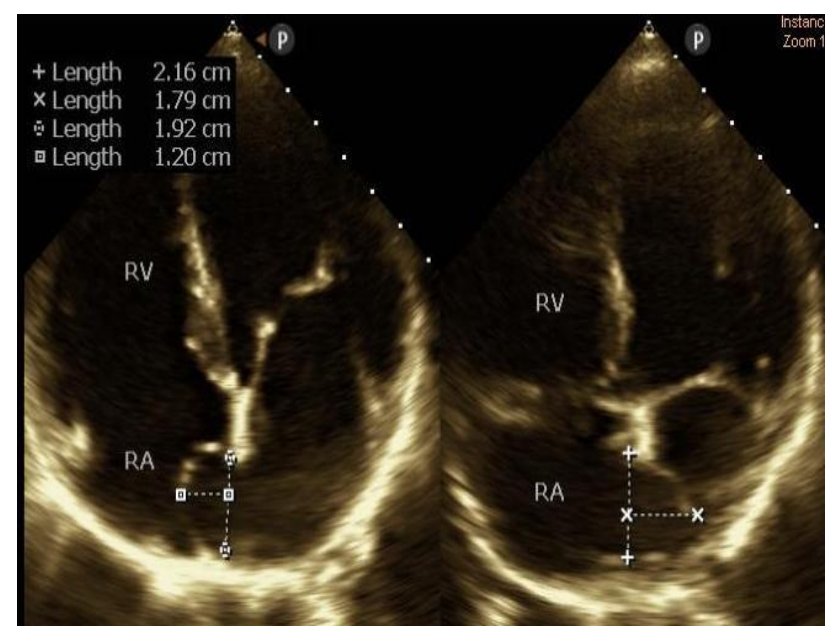

Figure 4: Localized Type 4 LR ASA; inverted AP4C view shows, maximal excursion of aneurysm toward LA (left frame) lesser excursion toward RA (Right frame).

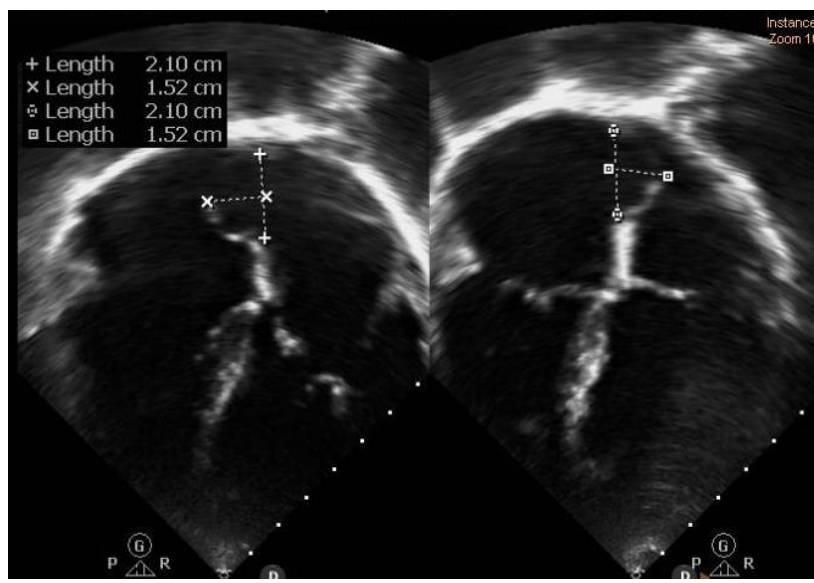

Figure 5: Localized Type 5 ASA; Apical four chamber view shows bidirectional and equidistance excursion of aneurysm in both atria.

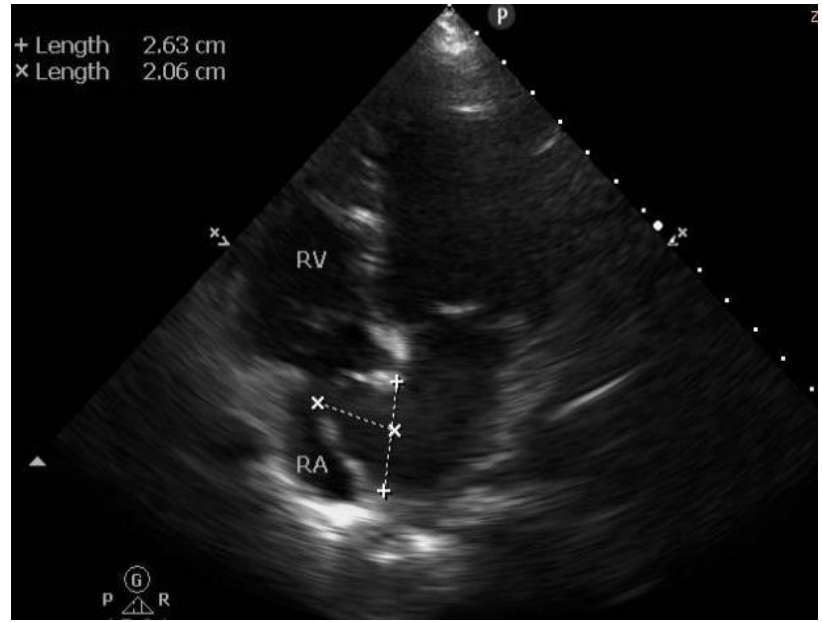

Figure 6: Inverted AP4C view shows generalized Type 1R ASA.

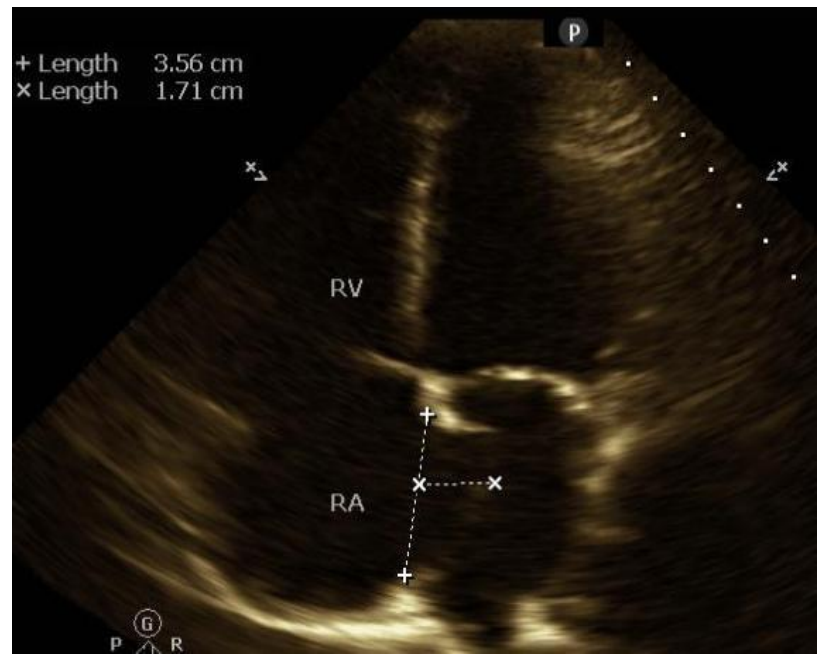

Figure 7: Inverted AP4C view shows generalized Type 2L ASA.

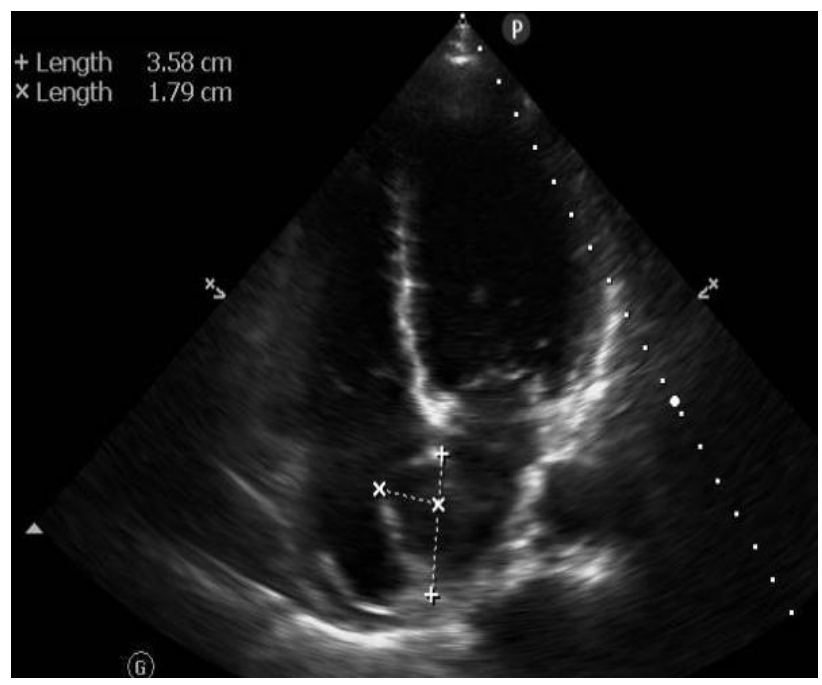

Figure 8(a): Generalized Type 3 RL ASA; inverted AP4C view shows, maximal excursion of aneurysm toward RA as compared from Figure 8(b). 


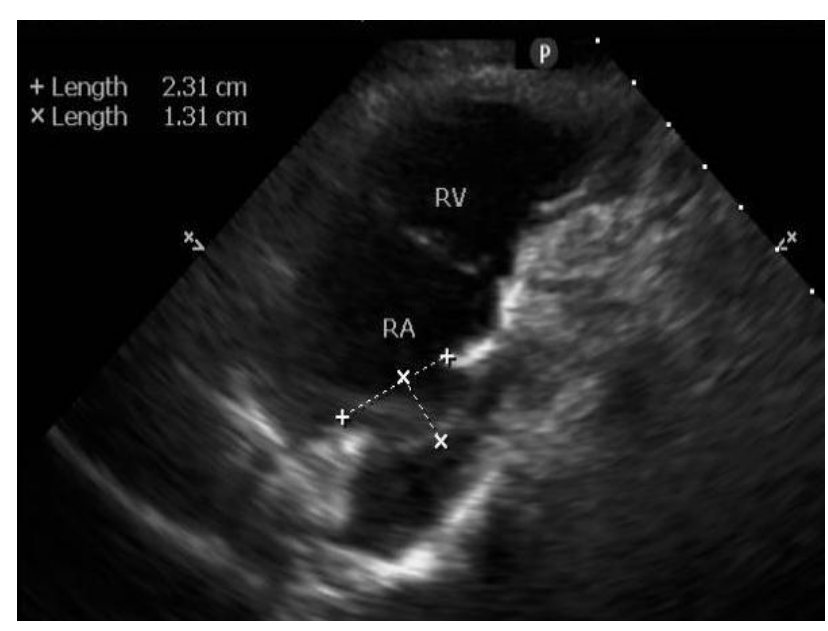

Figure 8(b): Generalized Type 3 RL ASA; sub-costal four chamber view shows, lesser excursion of aneurysm toward LA as compared from Figure 8(a).

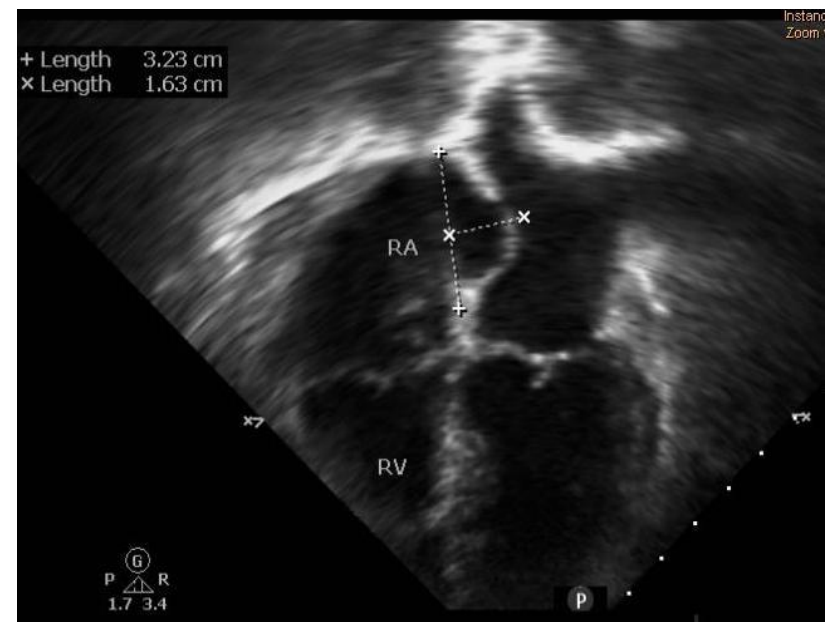

Figure 9(a): Generalized Type 4 LR ASA; AP4C view shows, maximal excursion of aneurysm toward LA as compare to Figure 9(b).

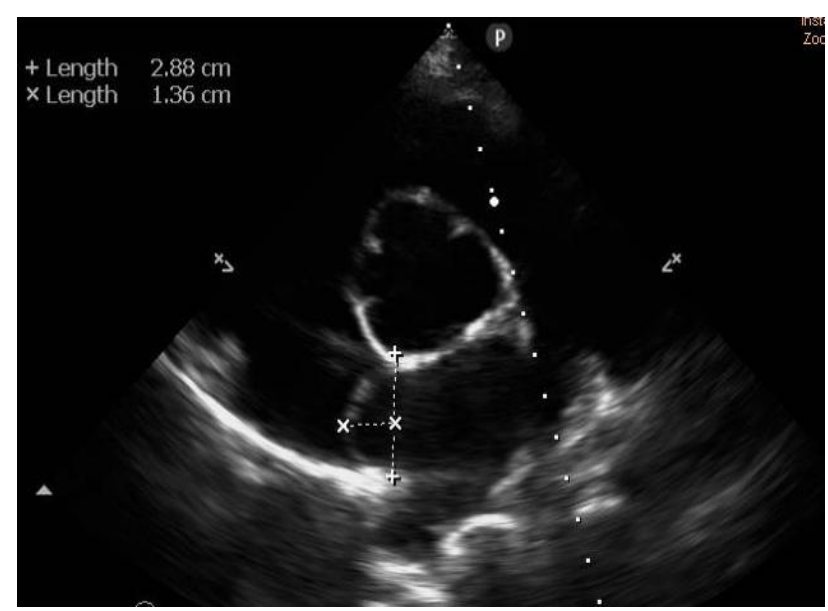

Figure 9(b): Generalized Type 4LR ASA; parasternal high short axis view shows, lesser excursion of aneurysm toward RA as compared from Figure 9(a).

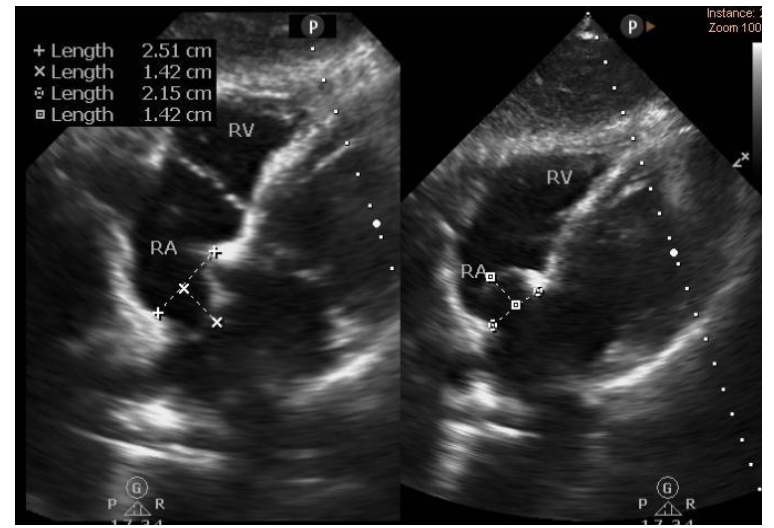

Figure 10: Generalized Type 5 ASA; sub-costal four chamber view shows bidirectional and equidistance excursion of aneurysm in both atria.

\section{DISCUSSION}

The first report on an atrial septal aneurysm was published by Lang and Posselt in $1934^{38}$ since than several ASA cases and studies have been published in the literature. An aneurysm of the interatrial septum is an infrequent finding in adults. ASA formations can be secondary to interatrial pressure differences but may also be a primary malformation involving the region of the fossa ovalis or the entire septum; ${ }^{1,9}$ however, it has been also found in patients with normal atrial pressure, ${ }^{23}$ suggesting a primary (Congenital) malformation. Congenital malformation of the atrial septum probably contributes to development of ASA, as was suggested by Hanley PC and colleagues. ${ }^{9}$ ASA may be an isolated cardiac abnormality but is often found in association with other cardiac abnormalities like CVE, SVTS etc..$^{9,11,28}$

There is a female predominance of ASA in our study. Although some reports also show this tendency $7,9,11,20,26$ other studies report no significant difference between genders. In fact some have reported a male predominance ${ }^{1,13,25,27}$ and others show a bimodal pattern in the prevalence of ASA with peaks during childhood and during older age. ${ }^{9,17,19,20}$ The prevalence of ASA is widely influenced by several factors like; (1) differing ASA diagnostic criteria (e.g. dimensional end point criteria $6 \mathrm{~mm},{ }^{7,33,34} 8 \mathrm{~mm},{ }^{11,14} 10 \mathrm{~mm},{ }^{34,35}$ or $15 \mathrm{~mm} ;{ }^{8,9,13,36}$ (2) Material, methodology, and equipment used (i.e. autopsy, TTE or TEE); (3) Population studied (i.e. children, adults, children and adults, elderly patients, or selected population like patients with CVE, MVP, interatrial shunting, etc.), and (4) lack of recognition or reporting of this entity by many echo-cardiographers until fairly recently (it has improved). In our study the prevalence of ASA (2.42\%) is higher than other publications, probably because of a combination of factors likes all patients were diagnosed by TTE, it is a single center study and patient's population was older. This prevalence figures may not reflect the general population because there is selection bias toward those who are referred for Echocardiographic evaluation. 


\section{Diagnostic criteria for ASA}

Even though this could be liberal criterion for ASA, we used a minimum dimension of $10 \mathrm{~mm}$, which is the same criterion used on autopsy studies. ${ }^{1}$ Some investigators use $6 \mathrm{~mm}^{7,22,33,37}$ but other uses $11 \mathrm{~mm} \& 15 \mathrm{~mm}^{8,9,13,38}$ as a cutoff. However, we believe $10 \mathrm{~mm}$ is more appropriate. The majority of our cases fell in the range of $10-15 \mathrm{~mm}$ (mean $14 \mathrm{~mm}$ ) of excursion. This dimension applies only for unidirectional ASA. For bidirectional the minimal measurement criteria is more than $10 \mathrm{~mm}$ in excursion.

\section{ASA classifications}

In 1985 Longhini et al. ${ }^{11}$ observed 3 motion patterns: (1) Type 1: the ASA projected into the RA during diastole, with easy systolic bulging into LA, followed by a rightward crossing over motion in mid systole and during inspiration or expiration. (2) Type 2: a sustained rightward deviation during expiration and a leftward motion occurred only during inspiration in early ventricular systole. (3) Type 3: the ASA remained in the RA, with an undulating motion during all phases of the cardiorespiratory cycle. That same year Hanley et al. ${ }^{9}$ classified ASA as follows: (1) Type 1A: the bulging in the RA being motionless. (2) Type 1B: the bulging confined to the RA but with rapid phasic oscillation during inspiration. (3) Type 2: the ASA protruding maximally into the LA and accompanied by excursion into the RA. Hanley's ASA types 1A and 1B were similar to those published by Longhini et al. In 1989 Roudaut et al. ${ }^{5}$ identified 3 distinct groups of ASA: (1) Type I: aneurysm involving only the fossa ovalis; (2) Type II: aneurysm involving the fossa ovalis and the posterior portion of the atrial septum (in type I and II, the ASA protrudes only to the RA), and (3) Type III: Aneurysm involving the entire atrial septum (type III protrudes only to the LA). In 1991 Pearson et al. ${ }^{18}$ in a TEE study added a new type of ASA - Type 1C. In four patients he observed that the ASA movement is predominantly to the RA with LA excursion during early systole. This movement was intensified by inspiration or Valsalva maneuver. In 1997 Alexander Olivares-Reyes et al. ${ }^{22}$ classified ASA in to 5 types: (1) Type 1R: the ASA protrudes from the midline of the atrial septum to the RA throughout the cardiorespiratory cycle (2) Type 2L: the ASA protrudes from the midline of the atrial septum to the LA throughout the cardiorespiratory cycle (3) Type 3RL: the maximal excursion of the ASA is toward the RA with a lesser excursion toward the LA (4) Type 4LR: the maximal excursion of the ASA is toward the LA with a lesser excursion toward the RA, (5) Type 5: the ASA movement is bidirectional and equidistant to the RA as well as to the LA during the cardiorespiratory cycle.

\section{Proposed new classification}

For five years we prospectively analyzed 370 consecutive patients in whom ASA was diagnosed by TTE. The direction and movement of atrial septal aneurysm were carefully studied in multiple views and according to our findings we are now proposing a new classification of atrial septal aneurysm. This new classification is very simple to understand, easy to recognize and very useful in clinical practice. The new classification we are proposing, attempts to include all possible excursions of ASA and to simplify the types of ASA described. We have classified ASA in two major types: (A) Localized, and (B) Generalized. Both are further sub-classified (Subdivided) into five possible types. Table 1 shows complete new classification of ASA. Figures from 1 to 10 shows originally recorded TTE images of all possible types of ASA.

Nomenclature of new classification: The first letter (A or B) tells us what the major type of ASA is. Letter A indicates Localized and letter B tells us generalized major type ASA. The consecutive numbers (1 through 5) cover all possible varieties of ASA movements. The second letter ( $\mathrm{R}$ for Right atrium and $\mathrm{L}$ for Left atrium) after the number ( 1 to 5 ) tell us immediately in which atrium the ASA is protruding (A/B Type $1 \mathrm{R}$ and A/B Type $2 \mathrm{~L}$ ), a third letter tells us bidirectional (A/B Type 3RL and 4LR) atrial septal aneurysms and which have excursion in both atria. In that case the first letter indicate the predominant direction of the protrusion and the letter in the second position tell us the lesser and opposite excursion. In case where the aneurysm bulges throughout both atria in an equal distance, this type is not followed by any letter and the number is used alone (A/B Type 5). This classification can give us a clue about some clinical association with other cardiac abnormalities as we saw in the clinical and Echocardiographic characteristics of each ASA type in our study, thus this new classification is more descriptive and very easy to remember.

The prevalence of presumed cardiogenic brain embolism varies between 22 and $39 \%$. ASA is one of the multiple causes of cardiac embolism. It has been speculated that ASA is a direct source of thrombus formation. ${ }^{8}$ This is supported by anecdotal findings demonstrating thrombotic material within the aneurysmal sac at autopsy ${ }^{1}$ or cardiac surgery. In our study 9 patients $(2.43 \%)$ had CVE with ASA (Table 7).

Cabanes et al. $^{33}$ found that ASA with $>10 \mathrm{~mm}$ of excursion and PFO are significantly are associated with a higher risk of stroke. In our study 5 patients had $>10 \mathrm{~mm}$ excursion of ASA, 3 had PFO and one had interatrial communication (Ostium secundum type of ASD). Siostrzonek $\mathrm{P}$ et al. $^{15}$ reported $20 \%$ versus $0 \%(\mathrm{P}=$ 0.0006) in the association of PFO and ASA in 99 patients with suspected cardiac source of embolism. Interatrial communication (ASD and PFO) and ASA showed a high association (up to 90\%) of causes with stroke., $90,10,26$ Echocardiographic differentiation between ASA-attached thrombi and artifacts created by mobile and bulging part of fossa ovalis may be difficult in some patients; a tangential scan through a mobile ASA may create the false impression of a thrombus. These difficulties in 
reliably differentiating between true thrombi and artifact may explain the differences in the incidence of thrombi attached to the ASA.Whether or not the echo densities that appear attached to an ASA are truly clots, the overall low incidence would suggest that an ASA on its own is unlikely to be a common site of thrombus formation. It should be noted; however TTE has a certain limit of resolution for thrombus detection. This resolution limit has not been defined and may be influenced by several factors, such as density of the thrombus and its relation to the surrounding blood and tissue. Thus this study does not exclude the possibility that small (micro) thrombi are attached to or at least generated in the region of ASA, subsequently causing cardiogenic embolism.

Atrial arrhythmias have been associated with atrial septal aneurysm. $^{29-31}$ It has been speculated that ASA movements initiate the arrhythmia. SVTA observed more with mobile type ASA. ${ }^{39}$ Lower incidence of atrial arrhythmias $(1.62 \%)$ in our study may be due to lower number of patients who had 24-hour ambulatory Holter monitoring. Although association with cardiac abnormalities can be arrhythmogenic, such as hypertension, atrial enlargement, valvular prolapses, systolic dysfunction or coronary artery disease.

MVP is one of the more frequent abnormalities seen with ASA. ${ }^{3,9,11,25,36}$ Some authors hypothesize that these two abnormalities have the same pathogenetic basis: a connective disorder involving fibrous tissue of the heart. $^{3,25,35} \mathrm{We}$ found lower percentage of valvular prolapses. MVP is more common with mobile variety of ASA.

Atrial shunting is the most common congenital association of ASA and has been found in up to $90 \%$ of patients with CVE; $77 \%$ had PFO, and 13\% had Ostium secundum type of ASD. ${ }^{10}$ In healthy adult subjects the prevalence of interatrial shunting attributed to PFO is $18 \%$. In contrast echocardiography studies the prevalence of ASD vary from $54 \%{ }^{39}$ to $77 \% .^{8}$ In autopsy series ${ }^{1,25,27}$ this association has been confirmed, as it has in cardiac surgery. ${ }^{9,10,24}$ Small number of contrast studies and low percentage of positive shunts are main limitation of our study. We attributed these limitations to our elderly population, some deficiency in the bubble studies in senile patients and all patients were diagnosed by TTE. Using TTE technique in adult patients, ASD has been reported in $13 \%$ and $15 \%$. $^{5}$ We observed low percentage of ASD. Explanation is same that is given for PFO.

\section{CONCLUSION}

We can conclude that ASA is more frequently detected and diagnosed now because of better cardiac ultrasound equipment and increased degree of suspicion for this entity. The new classification we proposed is a very simple, complete, easy to understand, easy to remember, decision making, very helpful for the physicians and practical form. ASA is more frequent in female patients. We found higher prevalence of ASA than other publications. This is a single center study, and findings may not be generalized to different populations.

\section{ACKNOWLEDGEMENTS}

The authors thank our research committee of CAIMS, for permission to publish this manuscript.

\section{Abbreviations}

ASA: Atrial septal aneurysm, CHD: Congenital heart disease, Th: Thrombus, Tu: Tumor, TIA: Transient ischemic attack, ECG: Electrocardiography, IAS: Inter atrial septum, TTE: Trans-thoracic two dimensional echocardiography, TEE: Trans-esophageal echocardiography, CVA: Cerebrovascular accident, AV valves: Atrioventricular valves, MVP: Mitral valve prolapse, TVP: Tricuspid valve prolapse, MS: Mitral valve stenosis, LV: Left ventricle, MI: Myocardial infarction, RBBB: Right bundle branch block, LBBB: Left bundle branch block, RA: Right atrium, LA: Left atrium.

\section{Funding: No funding sources \\ Conflict of interest: None declared}

Ethical approval: The study was approved by the institutional ethics committee

\section{REFERENCES}

1. Silver MD, Dorsey JS. Aneurysm of the septum Primum in the adults. Arch Path lab Med. 1978;102:62-5.

2. Peter C. Hanely, A. Jamil Tajik, John K. Hynes et al. Diagnosis and classification of atrial septal aneurysm by two-dimensional echocardiography: report of 80 consecutive cases. J Am Coll Cardiol. 1985;6(6):1370-82.

3. Iliceto S, Papa A, Sorino M, Rizzon P. Combined atrial septal aneurysm and mitral valve prolapse: detection by two-dimensional echocardiography. Am J Cardiol. 1984;54:1151-4.

4. Wilson JH, Lever HM, Moodie DS. Aneurysm of the interatrial septum. Cleve Clin Q. 1986;53:105-8.

5. Roudant R, Gosse R, Chague E, Dehant P, Choussat A, Dallochio M. Clinical and echocardiographic feature of the aneurysm on the atrial septum in infants and adults: experiences with 44 cases. Echocardiography. 1989;6:357-62.

6. Bewick DJ, Montague TJ. Atrial septal aneurysm: spectrum of clinical and echocardiographic presentation. Canadian Med Assoc J. 1987;136:60911.

7. Gallet B, Malergue Mc, Adam C, Saudemont JP, Collot AM, Druon MC et al. Atrial septal aneurysm: a potential cause of systemic embolism. Br Heart J. 1985;53:292-7. 
8. Schneider B, Hanrath $\mathrm{P}$, Vogel $\mathrm{P}$, Meinertz $\mathrm{T}$. Improved morphologic characterization of atrial septal aneurysm by transesophageal echocardiography: relation to cerebrovascular events. J Am Coll Cardiol. 1990;16:1000-9.

9. Hanley PC, Tajik AJ, Hynes JK, Edwads WD, Reeder GS, Hagker DJ et al. Diagnosis and classification of atrial septal aneurysm by twodimensiona echocardiography: report of 80 consecutive cases. J Am coll cardiol. 1985;6:137082.

10. Belkin RN, Hurwitz BJ, Kisslo J. Atrial septum aneurysm: associated with cerebrovascular and peripheral embolic events. Stroke. 1987;18:856-62.

11. Longhini C, Brunazzi MC, Musacci G, Caneva M, Bandello A, Bolomini L et al. Atrial septal aneurysm: echocardiographic study. Am J cardiol. 1985;56:653-67.

12. Ongelia C, Faggiano P, Sabatini T, Ghizzoni G, Rusconi C. Aneurisma del setto ed anomalie associate. Esperienza personale su 38 casi. Minerva Cardioangiol. 1993;41:95-100.

13. Zabalgoitia-Reyes M, Herrera C, Ghandi DK, Mehlman DJ, Mc Pherson DD, Talano JV. A possible mechanism for neurological ischemic events in patients with atrial septal aneurysm. Am J cardiol. 1990;66:761-4.

14. Katayama H, Mitamura H, Mitani K, Nakagawa S, Ui S, Kimura M. Incidence of atrial septal aneurysm: echocardiographic and pathologic analysis. J Cardiol. 1990;20:411-21.

15. Siostrzonek P, Lang W, Zangeneh M, Gossinger H, Stumpflen A, Rosenmayr G et al. Significance of left-sided heart disease for the detection of patent foramen ovale by transesophageal contrast echocardiography. J Am Coll Cardiol. 1992;19:1192-6.

16. Mirode A, Tribouilloy C, Boey S, Hadj Kacem L, Choqut D, Lesbre JP. Aneurysmes du septum interauriculaire. Apport de l'echographie transoesophagienne. Rlation avec les accidents systemiques emboliques. Ann Cariol Angeiol. 1993;42:7-12.

17. Shiraishi I, Hamaoka K, Hayashi S, Koh E, Onouchi Z, Sawas T. Atrial septal aneurysm in infancy. Pediatr Cardiol. 1990;11:82-5.

18. Pearson AC, Nagelhout D, Castello R, Gomez CR, Labovitz AJ. Atrial septal aneurysm and stroke. A transesophageal echocardiographic study. J Am Coll Cardiol. 1991;18:1223-9.

19. Brand A, Keren A, Branski D, Abrahamov A, Stern S. Natural course of atrial septal aneurysm in children and the potential for spontaneous closure of associated septal defect. Am J Cardiol. 1989;64:996-1001.

20. Wolf WJ, Casta A, Sapire DW. Atrial septal aneurysm in infants and children. Am Heart J. 1987;113:1149-53.

21. Levy D, Savage DD, Garrison RJ, Anderson KM, Kannel WB, Castelli WP. Echocardiographic criteria for left ventricular hypertrophy: the Framingham heart study. Am J Cardiol. 1987;59:956-60.

22. Alexander Olivares-Reyes, Samuel Chan, Eliot J. Lazer, Kishore Bandlamudi et al. Atrial septal aneurysm: a new classification in two hundred five adults. J Am Soci Echocardiography. 1997 July;6:644-56.

23. Hauser AM, Timmis GC, Stewart JR, Ramos RG, Gangadharan V, Westveer DC, Gordon S. Aneurysm of the atrial septum as diagnosed by echocardiography: analysis of 11 patients. Am J Cardiol. 1984;53:1401-2.

24. Gondi B, Nanda NC. Two dimensional Echocardiographic features of atrial septal aneurysm. Circulat. 1981;63:452-7.

25. Roberts WC. Aneurysm (redundancy) of the atrial septum (fossa ovalis membrane) and prolapse (redundancy) of the mitral valve. Am J Cardiol. 1984;54:1153-4.

26. Belkin RN, Waugh RA, Kisslo J. Interatrial shunting in atrial septal aneurysm. Am J Cardiol. 1986;57:310-2.

27. Topaz O, Feigl A, Edwards JE. Aneurysm of the fossa ovalis in infants: a pathological study. Pediatr cardiol. 1985;6:65-8.

28. Burstow DJ, Mc Eniery PT, Stafford EG. Fenestrated atrial septal aneurysm: diagnosed by transesophageal echocardiography. J Am So Echocardiog. 1990;3:499-501.

29. Rice MJ, Mc Donald RW, Reller MD. Fetal atrial septal aneurysm. A cause of fetal arrhythmias. J Am Coll Cardiol. 1988;12:1292-7.

30. Ong LS, Nanda NC, Falkoff MD, Barold SS. Interatrial septum aneurysm, systolic click and atrial tachyarrhythmia's-a new syndrome?. Ultrasound Biol. 1982;8:691-3.

31. Pernot G, Cloez JL, Khalife K, Had A, Marcon F. Dysrythemies supraventriculaires du nouveau-ne et aneurisme du septum interauricularie. Arch Fr Pediatr. 1984;41:21-5.

32. Toro L, Weintraub RG, Shiota T, Sahn DJ, Shan C, Mc Donald RW et al. Relation between persistent atrial arrhythmias and redundant septum Primum flap (atrial septal aneurysm) in fetuses. Am J Cardiol. 1994;73:711-3.

33. Cabanes L, Mas JL, Cohen A, Amarenco P, Cabanes PA, Oubary P et al. Atrial septal aneurysm and patent foramen ovale as risk factors for cryptogenic stroke in patients less than 55 years of age: a study using transesophageal echocardiography. Stroke. 1993;24:1865-73.

34. Mas JL, Arquizen C, Lamy C et al. Patent foramen ovale, and atrial septal aneurysm study group. Recurrent cerebrovascular events associated with patent foramen ovale, atrial septal aneurysm, or both. N Engl J Med. 2001;345:1740-6.

35. Rahko PS, Xu QR. Increased prevalence of atrial septal aneurysm in mitral valve prolapse. Am J cardiol. 1990;66:235-7. 
36. Barbosa MM, Pene JL, Motta MM, Fortes PR. Aneurysm of the atrial septum diagnosed by echocardiography and their associated cardiac abnormalities. Int J Cardiol. 1990;29:71-8.

37. Andreas Mugge, Werner G. Daniel, Christiane Angermann, Christoph Spes et al. atrial septal aneurysm in adults patients: a multicenter study using transthoracic and transesophageal echocardiography. Circulat. 1995;91:2785-92.

38. Lang FJ, Posselt A. Aneurrysmatische vorwolburg der fossa ovalis in den linken vorhof. Wiener Medizinische Wochenschrift. 1934;84:392-6.

39. Mugge A, Daniel WG, Angermann C, Spes C, Khandheria BK et al. Atrial septal aneurysm in adults patients: a multicenter study using transthoracic and transesophageal echocardiography. Circulat. 1995;19:2785-92.

40. Schneider B, Hofmann T, Meinertz T. Atrial septal aneurysm: is there an association between arrhythmias and stroke? Circulat. 1993;88(Suppl):1222.

DOI: 10.5455/2320-6012.ijrms20140564

Cite this article as: Jatav RK, Kumbhare MB, Surender T, Rachan C, Vamshi Krishna TV. Atrial septal aneurysm in adult patients: spectrum of clinical, echocardiographic presentation and to propose a new classification on the basis of trans-thoracic-twodimensional echocardiography. Int J Res Med Sci 2014;2:708-17. 